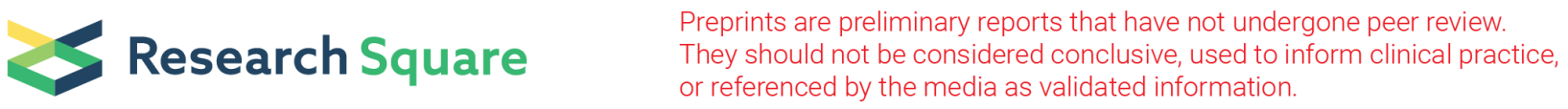

\title{
Abnormal TACC3 Expression is an Independent Prognostic Biomarker in Lung Carcinoma
}

\author{
Dongwei He ( $\nabla$ dongweihe@hebmu.edu.cn ) \\ Hebei Cancer Institute: Hebei Medical University Fourth Affiliated Hospital and Hebei Provincial Tumor Hospital \\ Xiaoyan Fan \\ Hebei General Hospital \\ Yulong Zhang \\ Shijiazhuang General Hospital \\ You Li \\ Hebei Cancer Institute: Hebei Medical University Fourth Affiliated Hospital and Hebei Provincial Tumor Hospital
}

\section{Research article}

Keywords: TACC3, prognosis, survival, outcome, lung carcinoma (LUAD)

Posted Date: December 7th, 2020

DOI: https://doi.org/10.21203/rs.3.rs-121095/v1

License: (1) This work is licensed under a Creative Commons Attribution 4.0 International License. Read Full License 


\section{Abstract}

Background: Abnormal expression of transforming acidic coiled-coil protein 3 (TACC3) correlates with tumorigenesis of many human malignancies. However, the expression pattern of TACC3 and its clinical significance have not been well characterized in lung carcinoma (LUAD) so far.

Objective: To investigate the association of TACC3 expression level with the clinicopathological characteristics and prognosis of LUAD patients.

Methods: In the study, based on Oncomine, Gene Expression Profiling Interactive Analysis (GEPIA), UALCAN, and The Cancer Genome Atlas (TCGA) databases, the expression of TACC3 was determined in LUAD patients. Further, the expression of TACC3 was established using qRT-PCR in LUAD patients.

Results: Our results showed that TACC3 was significantly overexpressed in LUAD tumors compared with non-tumors in the above public databases (all $p<0.01$ ). A receiver operating characteristic $(\mathrm{ROC})$ curve analysis suggested that TACC3 may have diagnostic value in LUAD patients (normal vs tumor: AUC $=0.940$ ). Kaplan-Meier analysis further demonstrated that high TACC3 expression in tumors was significantly associated with worse overall survival (OS) in LUAD patients (all $p<0.01$ ). In addition, Univariate and multivariate Cox regression analyses showed that TACC3 was an independent risk factor for OS among LUAD patients $(H R=1.02$, $95 \% \mathrm{Cl}: 1.01-1.04, p=0.00823 ; \mathrm{HR}=1.43,95 \% \mathrm{Cl}: 1.17-1.70, p<0.001)$. Finally, using gene set enrichment analysis (GSEA 3.0), we found that a series of potential pathways related to TACC3 were highly enriched with the high TACC3 expression phenotype $(p=$ $0.024, p=0.003$, respectively).

Conclusions: The present study provides evidence that TACC3 expression is upregulated in tumors and may be an independent risk factor for prognosis in LUAD patients.

\section{Introduction}

Lung cancer, which mainly includes small cell lung cancer and non-small cell lung cancer (NSCLC), represents the most common malignant tumor, and leads to substantial mortality worldwide[1]. NSCLC includes adenocarcinoma, squamous and large cell lung cancer [2]. The 5-year overall rate of patients with lung carcinoma (LUAD) has remained at a low level in China for the past 30 years [3]. Surgery, radiotherapy, chemotherapy, and targeted therapies are the first-line treatments for LUAD. However, the above treatment strategies often have limited effects on locally advanced, metastatic, and recurrent diseases, new therapeutic approaches are required for LUAD treatment [4]. Therefore, exploring the innate mechanism of LUAD to develop a novel therapeutic strategy is vitally important in the clinic.

TACC family members, which include TACC1, TACC2 and TACC3, were discovered for the first time in multiple myeloma [5]. In addition to keeping centrosomal microtubules nucleation and regulating of centrosomal integrity when mitosis occurs [6], TACC family has been established to be involved in tumorigenesis. Recently, abnormal expression of TACC1 and/or TACC3 was observed in ovarian, breast, melanoma, bladder, NSCLC and prostate cancers [7-12]. Abnormal expression of TACC2 was reported to be involved in prostate cancer [13], breast carcinoma and hepatocellular carcinoma [14, 15]. In addition, fibroblast growth factor (FGFR)1-TACC1 and FGFR3-TACC3 gene fusions, which are associated with aneuploidy and display oncogenic activities, has also been reported in various types of cancer patients $[16,17]$. These findings suggest that TACC 3 can potentially contribute to tumorigenesis.

Mounting evidences have shown that TACC3 overexpression is associated with tumor aggressiveness and poor prognosis in prostate cancer [8], breast cancer [7], colorectal cancer [9], gastric cancer [10], and human renal cell carcinoma cells [18]. However, the overexpression of TACC3 in LUAD remains largely unclear. To elucidate the relationship between TACC3 LUAD outcomes, we identified the expression and prognosis of TACC3 in LUAD patients using bioinformatics analysis. The present study indicates that TACC3 may be a potential prognosis biomarker in LUAD patients.

\section{Materials And Methods}




\section{Patient tissue specimens}

Fresh LUAD tissues $(n=6)$ from cases that were histologically confirmed and did not undergo any other treatments were obtained from The Fourth Hospital of Hebei Medical University. The study was approved by the Institute Research Ethics Committee at The Fourth Hospital of Hebei Medical University.

\section{Oncomine database analysis}

Oncomine Database is a powerful set of analysis functions that compute gene expression signatures, clusters and gene-set modules, automatically extracting biological insights from 715 datasets and 86733 samples

(https://www.oncomine.org/resource/login.html) [19]. Here, the expression levels of TACC3 in LUAD were determined by Oncomine Database analysis. The thresholds ( $p$ : 0.0001 , fold change:1.5, and gene rank: all) were considered as statistically significant.

\section{GEPIA database analysis}

GEPIA (http://gepia.cancer-pku.cn/) is a newly developed interactive web server for analyzing the RNA sequencing expression data of 9,736 tumors and 8,587 normal samples from the TCGA and the GTEx projects, using a standard processing pipeline [20]. In the single gene expression analysis, TACC3 expression was determined in LUAD, with the following thresholds: $\left|\log _{2}\right| \mathrm{FC}$ cutoff $=0.5$ and $p$-value cutoff $=0.01$. In the survival analysis, the threshold was determined according to the following values: group cutoff: median; cutoff-high (\%) and cutoff-low (\%): 50 and 50.

\section{UALCAN database analysis}

UALCAN is a comprehensive, and interactive web resource (http://ualcan.path.uab.edu/index.html) for analyzing cancer OMICS data [21]. It is designed to provide easy access to publicly available cancer OMICS data (TCGA and MET500), thus allow us to identify biomarkers of interest. Here, the expression and survival of TACC3 were selected from TCGA databases and $p<0.05$ was considered significant.

\section{TCGA database analysis}

Gene expression data and patient data in LUAD were downloaded from Genomic Data commons (GDC) (https://portal.gdc.cancer.gov/) using GDC data transfer tool. Gene expression data were analyzed by R (version:3.6.1) with related $\mathrm{R}$ packages. Clinical parameters, such as age, gender, survival status, tumor stage and so on, were extracted from the patient data and were matched to each patient by the PERL script.

\section{Kaplan-Meier Plotter database analysis}

Based on a meta-analysis, the Kaplan Meier plotter (http://kmplot.com/analysis/) is capable to assess the effect of 54,000 genes on survival in 21 cancer types [22]. The correlation between TACC3 and survival (OS and First Progression, FP) in LUAD was analyzed using mRNA data. Patients were split by median, and the cutoff value was set as auto select.

\section{ROC curve generation}

ROC curves were generated to evaluate the diagnostic value of TACC3 using IBM SPSS Statistics 26 . And the AUC of each curve was also determined and showed in each panel.

\section{Kyoto encyclopedia of genes and genomes (KEGG) analysis}

To identify potential mechanisms underlying the influence of TACC3 expression on LUAD, KEGG analysis was performed to detect whether an a priori defined set of genes showed statistically significant differential expression between the high and low TACC3 expression groups [23]. Gene sets with a normal $p$-value $<0.05$ and false discovery rate (FDR) $<0.05$ were considered significantly enriched.

\section{RNA extraction and qRT-PCR methods}


qRT-PCR was performed to determine the expression of TACC3 mRNA. Briefly, total RNA from the surgically obtained paired tissues $(n=6)$ was isolated using TRI Reagent RNA Isolation Reagent (Sigma-Aldrich) according to the manufacturer's instructions. A reverse transcription system was used to obtain first-strand template Complementary DNA (CDNA). The primer sequences used were as follows: TACC3: 5'-CCTCTTCAAGCGTTTTGAGAAAC-3' (sense) and 5'-GCCCTCCTGGGTGATCCTT-3' (antisense); $\beta$-actin: 5'CGCGAG AAGATGACCCAGAT-3' (sense) and 5'-GGGCATACCCCT CGTAGATG-3' (antisense)[10, 18]. The expression of $\beta$-actin was considered as an internal control. The PCR reaction was determined as follows: denaturation at $94^{\circ} \mathrm{C}$ for 3 minutes, and then 35 cycles of $94^{\circ} \mathrm{C}$ for 30 seconds, $56^{\circ} \mathrm{C}$ for 30 seconds, $72^{\circ} \mathrm{C}$ for 2 minutes, and finally elongation step of $72^{\circ} \mathrm{C}$ for 10 minutes. Three independent experiments were performed to confirm the quantitation of the results.

\section{Statistical analysis}

All analyses of the TCGA data were conducted using R software (version 3.6.1). Univariate Cox regression analysis was used to select potential prognostic factors, and multivariate Cox analysis was performed to verify the correlations between TACC3 expression and survival along with other clinical features. Statistical analyses were performed using GraphPad Prism 8.0 software (GraphPad). $p<0.05$ was considered statistically significant.

\section{Results}

\section{Characteristics of the patients from TCGA}

The clinical data of 467 patients were downloaded from TCGA database, including age, gender, stage, TMN classification and survival status (Table 1). 
Table 1

Clinical characteristics of the 467 LUAD patients downloaded from the TCGA database.

\begin{tabular}{|c|c|}
\hline Characteristic & $\mathbf{N}(\%)$ \\
\hline \multicolumn{2}{|l|}{ Age (years) } \\
\hline$\leq 60$ & $155(33.19)$ \\
\hline$>60$ & $312(66.81)$ \\
\hline \multicolumn{2}{|l|}{ Gender } \\
\hline Female & 254 (54.39) \\
\hline Male & $213(45.61)$ \\
\hline \multicolumn{2}{|l|}{ Stage } \\
\hline I & $251(53.75)$ \\
\hline ॥ & $108(21.13)$ \\
\hline III & 75 (16.06) \\
\hline IV & $25(5.35)$ \\
\hline Not available & $8(3.71)$ \\
\hline \multicolumn{2}{|l|}{ T classification } \\
\hline T1 & $162(34.69)$ \\
\hline T2 & $244(52.25)$ \\
\hline T3 & 39 (8.35) \\
\hline $\mathrm{T} 4$ & 19 (4.07) \\
\hline TX & $3(0.64)$ \\
\hline \multicolumn{2}{|l|}{ M classification } \\
\hline MO & $314(67.24)$ \\
\hline M1 & $24(5.14)$ \\
\hline$M X$ & $125(26.77)$ \\
\hline Not available & $4(0.85)$ \\
\hline \multicolumn{2}{|l|}{$\mathrm{N}$ classification } \\
\hline No & $300(64.24)$ \\
\hline N1 & 87 (18.63) \\
\hline N2 & $66(14.13)$ \\
\hline N3 & $2(0.43)$ \\
\hline NX & $11(2.36)$ \\
\hline Not available & $1(0.21)$ \\
\hline \multicolumn{2}{|l|}{ Survival status } \\
\hline Death & $158(33.83)$ \\
\hline Survival & 309 (66.17) \\
\hline
\end{tabular}

Page 5/21 


\section{High Tacc3 Mrna Expression In Luad}

Based on Oncomine, GEPIA and UALCAN databases, TACC3 mRNA expression in LUAD was determined, respectively. Levels of TACC3 expression were higher in LUAD tissues, compared to the normal tissues (Fig. 1A-C). The results were further confirmed by TCGA database ( $p=2.672 \mathrm{e}-11$, Fig. 1D). In addition, there was a significant difference in TACC3 expression in a paired comparison of LUAD and their adjacent normal tissues ( $p=2.343 \mathrm{e}-15$, Fig. 1E). These results suggested that TACC3 was highly expressed in LUAD compared with normal tissues.

\section{Prognostic Potential Of Tacc3 In Luad}

The role of TACC3 expression on prognostic potential of LUAD patients was determined by Kaplan-Meier Plotter, GEPIA, UALCAN, and TACG databases. No significant difference was found in disease free survival (DFS) by GEPIA (log rank $p=0.05, \mathrm{HR}=1.4$, Fig. 2D). However, high TACC3 mRNA expression was significantly associated with poor OS of LUAD patients in Kaplan-Meier Plotter (Log rank $p=1.7 \mathrm{e}-07, \mathrm{HR}=1.88$; Fig. 2B), UALCAN ( $p<0.0001$, Fig. 2C), GEPIA (Log rank $p=1 \mathrm{e}-04, \mathrm{HR}=1.8$, Fig. 2E), and TCGA analyzed by $\mathrm{R}(p=0.002$, Fig. $2 \mathrm{~F})$. In addition, high TACC3 mRNA expression was significantly associated with poor FP of LUAD patients in Kaplan-Meier Plotter (Log rank $p=5.3 \mathrm{e}-05, \mathrm{HR}=1.91$; Fig. 2A) These results indicated that TACC3 expression had a large impact on the survival of LUAD patients.

\section{Role Of Tacc3 In Clinical Characteristics Of Luad}

To evaluate the role of TACC3 in clinical characteristics of LUAD, the relationship between TACC3 expression and clinicopathological characteristics was determined using Kaplan-Meier plotter. As shown in Table 2, TACC3 mRNA expression was negatively associated with OS in female and male patients $(p=0.0084, \mathrm{p}=9.1 \mathrm{e}-4$, respectively), as well as in smoked LUAD patients $(p=0.008)$. Obviously, high expression of TACC3 was associated with worse OS in stage 1, 3, AJCC stage T1, stage N0, and M0 patients ( $\mathrm{p}=9.7 \mathrm{e}-5, p=0.023, p=5.2 \mathrm{e}-4, p=0.0035$ and $p=7.6 \mathrm{e}-4$, respectively). Meanwhile, TACC3 expression was associated with FP in male, never smoked, and stage 1 LUAD patients ( $p=5.1 \mathrm{e}-4, p=0.027$ and $p=0.0058$, respectively). In addition, no significant difference was observed in the relationship between TACC3 expression and PPS of LUAD patients. These results suggested that TACC3 expression mainly affected the OS of LUAD patients. 
Table 2

Correlation of TACC3 mRNA expression and clinical prognosis in LUAD with different clinicopathological factors by Kaplan-Meier plotter.

\begin{tabular}{|c|c|c|c|c|c|c|c|c|c|}
\hline \multirow{2}{*}{$\begin{array}{l}\text { Clinicopathological } \\
\text { characteristics }\end{array}$} & \multicolumn{3}{|l|}{ os } & \multicolumn{3}{|l|}{ FP } & \multicolumn{3}{|l|}{ PPS } \\
\hline & $\mathbf{N}$ & $\begin{array}{l}\mathrm{HR} \\
(95 \% \mathrm{Cl})\end{array}$ & $\begin{array}{l}\text { Log rank } \\
\mathrm{P}\end{array}$ & $\mathbf{N}$ & $\begin{array}{l}\mathrm{HR} \\
(95 \% \mathrm{Cl})\end{array}$ & $\begin{array}{l}\text { Log rank } \\
P\end{array}$ & $\mathbf{N}$ & $\begin{array}{l}\mathrm{HR} \\
(95 \% \mathrm{Cl})\end{array}$ & $\begin{array}{l}\text { Log } \\
\text { rankP }\end{array}$ \\
\hline \multicolumn{10}{|l|}{ Gender } \\
\hline Female & 318 & $\begin{array}{l}1.67(1.14- \\
2.46)\end{array}$ & $0.0084 * \star$ & 235 & $\begin{array}{l}1.52(0.96- \\
2.4)\end{array}$ & 0.071 & 59 & $\begin{array}{l}1.19(0.6- \\
2.38)\end{array}$ & 0.62 \\
\hline Male & 344 & $\begin{array}{l}1.75(1.25- \\
2.44)\end{array}$ & $\begin{array}{l}9.1 \mathrm{e}- \\
4^{\star \star \star}\end{array}$ & 226 & $\begin{array}{l}2.16(1.38- \\
3.37)\end{array}$ & $\begin{array}{l}5.1 \mathrm{e}- \\
4^{\star \star \star}\end{array}$ & 125 & $\begin{array}{l}0.72(0.38- \\
1.37)\end{array}$ & 0.32 \\
\hline \multicolumn{10}{|l|}{ Smoking history } \\
\hline Never smoked & 22 & $\begin{array}{l}1.47(0.2- \\
10.89)\end{array}$ & 0.7 & 143 & $\begin{array}{l}2.01(1.07- \\
3.78)\end{array}$ & $0.027^{*}$ & 41 & $\begin{array}{l}0.62(0.26- \\
1.48)\end{array}$ & 0.27 \\
\hline Smoked & 246 & $\begin{array}{l}1.91(1.17- \\
3.11)\end{array}$ & $0.008^{\star *}$ & 461 & $\begin{array}{l}1.51(0.97- \\
2.33)\end{array}$ & 0.064 & 82 & $\begin{array}{l}0.84(0.47- \\
1.48)\end{array}$ & 0.54 \\
\hline \multicolumn{10}{|l|}{ Stage } \\
\hline 1 & 370 & $\begin{array}{l}2.25(1.48- \\
3.42)\end{array}$ & $\begin{array}{l}9.7 \mathrm{e}- \\
5^{\star \star \star}\end{array}$ & 283 & $\begin{array}{l}1.99(1.21- \\
3.27)\end{array}$ & $0.0058^{\star \star}$ & 66 & $\begin{array}{l}1.06(0.53- \\
2.1)\end{array}$ & 0.88 \\
\hline 2 & 105 & $\begin{array}{l}1.62(0.93- \\
2.80)\end{array}$ & 0.085 & 103 & $\begin{array}{l}0.94(0.54- \\
1.64)\end{array}$ & 0.84 & 38 & $\begin{array}{l}0.52(0.23- \\
1.15)\end{array}$ & 0.099 \\
\hline 3 & 24 & $\begin{array}{l}3.54(1.11- \\
11.26)\end{array}$ & $0.023^{*}$ & 10 & - & - & 1 & - & - \\
\hline 4 & 4 & - & - & 0 & & & 0 & - & - \\
\hline \multicolumn{10}{|l|}{ AJCC stage $T$} \\
\hline 1 & 123 & $\begin{array}{l}3.18(1.6- \\
6.32)\end{array}$ & $\begin{array}{l}5.2 \mathrm{e}- \\
4^{\star \star \star}\end{array}$ & 47 & $\begin{array}{l}1.56(0.35- \\
7)\end{array}$ & 0.56 & 7 & & \\
\hline 2 & 105 & $\begin{array}{l}1.62(0.93- \\
2.8)\end{array}$ & 0.085 & 93 & $\begin{array}{l}1.62(0.86- \\
3.06)\end{array}$ & 0.13 & 38 & $\begin{array}{l}0.52(0.23- \\
1.15)\end{array}$ & 0.099 \\
\hline 3 & 4 & - & - & 2 & - & - & 1 & - & - \\
\hline 4 & 0 & - & - & 0 & - & - & 0 & - & - \\
\hline \multicolumn{10}{|l|}{ AJCC stage $\mathrm{N}$} \\
\hline 0 & 184 & $\begin{array}{l}2.07(1.26- \\
3,4)\end{array}$ & $0.0035^{\star \star}$ & 102 & $\begin{array}{l}1.31(0.61- \\
2.84)\end{array}$ & 0.49 & 25 & $\begin{array}{l}0.73(0.27- \\
1.95)\end{array}$ & 0.53 \\
\hline 1 & 44 & $\begin{array}{l}1.15(0.53- \\
2.49)\end{array}$ & 0.72 & 38 & $\begin{array}{l}1.24(0.5- \\
3.06)\end{array}$ & 0.65 & 19 & - & - \\
\hline 2 & 3 & - & - & 2 & - & - & 2 & - & - \\
\hline \multicolumn{10}{|l|}{ AJCC stage M } \\
\hline 0 & 231 & $\begin{array}{l}1.99(1.32- \\
2.99)\end{array}$ & $\begin{array}{l}7.6 \mathrm{e}- \\
4 * \star \star\end{array}$ & 142 & $\begin{array}{l}1.73(0.97- \\
3.09)\end{array}$ & 0.06 & 46 & $\begin{array}{l}0.62(0.3- \\
1.28)\end{array}$ & 0.19 \\
\hline 1 & 1 & - & - & 0 & - & - & 0 & - & - \\
\hline
\end{tabular}


To further elucidate the role of TACC3 in diagnostic value in LUAD patients, ROC curves were generated by SPSS26.0. The AUC was 0.940 , which suggested that the level of TACC3 mRNA expression was a strong diagnostic value in LUAD (Fig. 3A). In addition, we further determined the diagnostic value of TACC3 in stage I, II, III, and IV of LUAD (Fig. 3B-3E). The AUCs were 0.930, $0.956,0.973$, and 0.904 , respectively. These results indicated that TACC3 could be a potential diagnostic biomarker in LUAD.

\section{High TACC3 expression could be an independent risk factor for OS among LUAD patients}

To understand whether TACC3 was an independent risk factor for OS of LUAD patients, univariate and multivariate Cox regression analyses were detected using the R script. In univariate Cox analysis, stage, $\mathrm{T}$ and $\mathrm{N}$ classification, and TACC3 were independent risk factors ( $p=3.07 \mathrm{e}-11,2.24 \mathrm{e}-5,7.17 \mathrm{e}-9$, and 8.23e-3, respectively, Table 3); while in multivariate Cox analysis, only stage and TACC3 were independent risk factors ( $p=2.2 \mathrm{e}-4$, and $p=4.1 \mathrm{e}-4$, respectively). The results indicated that TACC3 expression was an independent risk factor for OS among LUAD patients ( $\mathrm{HR}=1.43,95 \% \mathrm{Cl}: 1.17-1.7, p<0.001$, Fig. 4).

Table 3

Univariate and multivariate analysis of the correlation of TACC3 expression with OS among LUAD patients.

\begin{tabular}{|c|c|c|c|c|c|c|}
\hline \multirow[t]{2}{*}{ Parameter } & \multicolumn{3}{|c|}{ Univariate analysis } & \multicolumn{3}{|c|}{ Multivariate analysis } \\
\hline & HR & $95 \% \mathrm{Cl}$ & p-value & HR & $95 \% \mathrm{Cl}$ & p-value \\
\hline Age & 1.01 & $1.00-1.03$ & 0.15 & & & \\
\hline Gender & 1.08 & $0.79-1.49$ & 0.62 & & & \\
\hline Stage & 1.65 & $1.43-1.92$ & $3.07 e-11^{\star \star \star \star}$ & 1.51 & $1.21-1.87$ & $2.2 \mathrm{e}-4^{\star \star \star}$ \\
\hline T classification & 1.53 & $1.26-1.87$ & $2.24 \mathrm{e}-5^{\star \star \star \star}$ & 1.16 & $0.94-1.44$ & 0.15 \\
\hline $\mathrm{N}$ classification & 1.70 & $1.42-2.03$ & 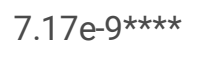 & 1.14 & $0.90-1.46$ & 0.28 \\
\hline TACC3 & 1.02 & $1.01-1.04$ & $0.00823^{\star *}$ & 1.43 & $1.17-1.70$ & $4.1 \mathrm{e}-4^{\star \star \star}$ \\
\hline
\end{tabular}

\section{High Expression Of Tacc3 Mrna In Luad Fresh Tissues}

To confirm the TACC3 mRNA expression in LUAD, we finally performed Real-Time PCR in 6 pair of matched LUAD tissues and their adjacent noncancerous tissues. As shown in Fig. 6, the expression of TACC3 mRNA was upregulated in LUAD cancer tissues, compared with that in the corresponding noncancerous tissues $(p=0.0052)$.

\section{Discussion}

Increasing evidences suggest that TACC3 is associated with various types of human cancers, including breast cancer [7, 24, 25], prostate cancer [8], colorectal cancer [9], bladder cancer [26], gastric cancer [10], ovarian cancer [27], melanoma cancer [28], and liver cancer [29]. However, few studies have investigated TACC3 expression in LUAD. Recently, genomic alterations in FGFR family members have been reported in several tumors including breast cancer, bladder cancer, prostate cancer, and lung cancer. FGFR3TACC3 fusions have been identified as new genomic alterations in LUAD patients who mostly never/limited smoked cigarettes [16]. Therefore, these results suggest that TACC3 may play an important role in LUAD progression. The present study demonstrated a possible relationship between TACC3 expression and patient survival in LUAD, and further validated the function using Cox regression and ROC curve analyses.

In the present study, to eliminate the discrepancies of TACC3 expression and prognostic potential in LUAD, various types of databases, included Oncomine, TMIER, Kaplan-Meier plotter, GEPIA, UALCAN, and TCGA were analyzed, respectively. Though different databases and methods were used in the study, similar results were finally found in Figs. 1 and 2. Our study suggested that abnormal high TACC3 expression was associated with poor survival in LUAD, suggesting that TACC3 may play a vital role in 
LUAD progression. Univariate and multivariate Cox analyses indicated that TACC3 expression may be a valuable prognostic biomarker for LUAD prognosis, and ROC curve analysis further strongly validated the diagnostic value of TACC3 in LUAD.

Increasing studies have reported the possible mechanisms to explain the relationship between TACC3 expression and patient prognosis in malignant cancers. TACC3 could promote epithelial-mesenchymal transition (EMT) phenotype through activation of $\mathrm{PI} 3 \mathrm{~K} / \mathrm{AKT}$ and ERK signaling pathways in cervical cancer [11]. Meanwhile, TACC3 knockdown could inactivate PI3K/AKT signaling in kidney renal clear cell carcinoma [18]. Based on these reports, TACC3 may contribute to affect EMT phenotype by regulating that PI3K/AKT signaling in cancers. While in the current study, using GSEA3.0 software, we found no significant difference in the enrichment of PI3K/AKT signal pathway in LUAD. The discrepancy could be explained by different raw data, and/or different calculating methods used in the study. More experiments should be done to confirm this in the near future. However, we further found that cancer-associated signaling pathways, including non-small cell lung cancer and small cell lung cancer, as well as other types of tumors were associated with high TACC3 expression phenotype, indicating that TACC3 may be closely involved various types of cancers (Table 4).

In summary, based on Oncomine and TCGA databases, we observed that high TACC3 expression was associated with poor prognosis in LUAD. And the result was further validated by Cox regression and ROC analyses. Therefore, TACC3 may be a prognosis biomarker in LUAD patients.

\section{Abbreviations}

TACC3 transforming acidic coiled-coil protein 3

LUAD lung carcinoma

GEPIA Gene Expression Profiling Interactive Analysis

TCGA The Cancer Genome Atlas databases

ROC receiver operating characteristic curve

OS overall survival

KEGG Kyoto encyclopedia of genes and genomes analysis

\section{Declarations}

\section{Acknowledgements}

The present study was supported by Natural Science Foundation of Hebei Province (H20206360), Projects from Health and Family Planning Commission of Hebei Province (Grant No.20190738, 20190007, 20200745 and 20200573).

\section{Author's contributions}

XY F and DW H designed the studies and finished most of the work. YL Z and DW H wrote the paper. Part of TAGA analysis were performed by $Y \mathrm{~L}$.

\section{Conflict of interests}

The authors have declared that no competing interest exists.

\section{References}

1. Siegel RL, Miller KD, Jemal A. Cancer statistics, 2016. CA Cancer J Clin. 2016;66(1):7-30.

2. Torre LA, Siegel RL, Jemal A. Lung Cancer Statistics. Adv Exp Med Biol. 2016;893:1-19.

Page 9/21 
3. Jemal A, Siegel R, Xu J, Ward E. Cancer statistics, 2010. CA Cancer J Clin. 2010;60(5):277-300.

4. Fan XY, Wang PY, Zhang C, Zhang YL, Fu Y, Zhang C, Li QX, Zhou JN, Shan BE, He DW. All-trans retinoic acid enhances cytotoxicity of CIK cells against human lung adenocarcinoma by upregulating MICA and IL-2 secretion. Sci Rep. 2017;7(1):16481.

5. Still IH, Vince P, Cowell JK. The third member of the transforming acidic coiled coil-containing gene family, TACC3, maps in $4 \mathrm{p} 16$, close to translocation breakpoints in multiple myeloma, and is upregulated in various cancer cell lines. Genomics. 1999;58(2):165-70.

6. LeRoy PJ, Hunter JJ, Hoar KM, Burke KE, Shinde V, Ruan J, Bowman D, Galvin K, Ecsedy JA. Localization of human TACC3 to mitotic spindles is mediated by phosphorylation on Ser558 by Aurora A: a novel pharmacodynamic method for measuring Aurora A activity. Cancer Res. 2007;67(11):5362-70.

7. Song H, Liu C, Shen N, Yi P, Dong F, Li X, Zhang N, Huang T. Overexpression of TACC3 in Breast Cancer Associates With Poor Prognosis. Appl Immunohistochem Mol Morphol. 2018;26(2):113-9.

8. Li Q, Ye L, Guo W, Wang M, Huang S, Peng X. Overexpression of TACC3 is correlated with tumor aggressiveness and poor prognosis in prostate cancer. Biochem Biophys Res Commun. 2017;486(4):872-8.

9. Du Y, Liu L, Wang C, Kuang B, Yan S, Zhou A, Wen C, Chen J, Wu Y, Yang X, et al. TACC3 promotes colorectal cancer tumourigenesis and correlates with poor prognosis. Oncotarget. 2016;7(27):41885-97.

10. Yun M, Rong J, Lin ZR, He YL, Zhang JX, Peng ZW, Tang LQ, Zeng MS, Zhong Q, Ye S. High expression of transforming acidic coiled coil-containing protein 3 strongly correlates with aggressive characteristics and poor prognosis of gastric cancer. Oncol Rep. 2015;34(3):1397-405.

11. Ha GH, Park JS, Breuer EK. TACC3 promotes epithelial-mesenchymal transition (EMT) through the activation of PI3K/Akt and ERK signaling pathways. Cancer Lett. 2013;332(1):63-73.

12. Cully M, Shiu J, Piekorz RP, Muller WJ, Done SJ, Mak TW. Transforming acidic coiled coil 1 promotes transformation and mammary tumorigenesis. Cancer Res. 2005;65(22):10363-70.

13. Takayama K, Horie-Inoue K, Suzuki T, Urano T, Ikeda K, Fujimura T, Takahashi S, Homma Y, Ouchi Y, Inoue S. TACC2 Is an Androgen-Responsive Cell Cycle Regulator Promoting Androgen-Mediated and Castration-Resistant Growth of Prostate Cancer. Mol Endocrinol. 2012;26(5):748-61.

14. Onodera Y, Takagi K, Miki Y, Takayama K, Shibahara Y, Watanabe M, Ishida T, Inoue S, Sasano H, Suzuki T. TACC2 (transforming acidic coiled-coil protein 2) in breast carcinoma as a potent prognostic predictor associated with cell proliferation. Cancer Med. 2016;5(8):1973-82.

15. Shakya M, Zhou A, Dai D, Zhong Q, Zhou Z, Zhang Y, Li X, Bholee AK, Chen M. High expression of TACC2 in hepatocellular carcinoma is associated with poor prognosis. Cancer Biomarkers. 2018;22(4):611-9.

16. Capelletti M, Dodge ME, Ercan D, Hammerman PS, Park SI, Kim J, Sasaki H, Jablons DM, Lipson D, Young L, et al. Identification of recurrent FGFR3-TACC3 fusion oncogenes from lung adenocarcinoma. Clin Cancer Res. 2014;20(24):6551-8.

17. Frattini V, Pagnotta SM, Tala, Fan JJ, Russo MV, Lee SB, Garofano L, Zhang J, Shi P, Lewis G, et al. A metabolic function of FGFR3-TACC3 gene fusions in cancer. Nature. 2018;553(7687):222-7.

18. Guo F, Liu Y. Knockdown of TACC3 Inhibits the Proliferation and Invasion of Human Renal Cell Carcinoma Cells. Oncol Res. 2018;26(2):183-9.

19. Rhodes DR, Kalyana-Sundaram S, Mahavisno V, Varambally R, Yu J, Briggs BB, Barrette TR, Anstet MJ, Kincead-Beal C, Kulkarni P, et al. Oncomine 3.0: genes, pathways, and networks in a collection of 18,000 cancer gene expression profiles. Neoplasia. 2007;9(2):166-80.

20. Tang Z, Li C, Kang B, Gao G, Li C, Zhang Z. GEPIA: a web server for cancer and normal gene expression profiling and interactive analyses. Nucleic Acids Res. 2017;45(W1):W98-102.

21. Chandrashekar DS, Bashel B, Balasubramanya SAH, Creighton CJ, Ponce-Rodriguez I, Chakravarthi B, Varambally S. UALCAN: A Portal for Facilitating Tumor Subgroup Gene Expression and Survival Analyses. Neoplasia. 2017;19(8):649-58.

22. Nagy A, Lanczky A, Menyhart O, Gyorffy B. Validation of miRNA prognostic power in hepatocellular carcinoma using expression data of independent datasets. Sci Rep. 2018;8(1):9227.

Page $10 / 21$ 
23. Subramanian A, Tamayo P, Mootha VK, Mukherjee S, Ebert BL, Gillette MA, Paulovich A, Pomeroy SL, Golub TR, Lander ES, et al. Gene set enrichment analysis: a knowledge-based approach for interpreting genome-wide expression profiles. Proc Natl Acad Sci U S A. 2005;102(43):15545-50.

24. Stanton SE, Disis ML. Clinical significance of tumor-infiltrating lymphocytes in breast cancer. J Immunother Cancer. 2016;4:59.

25. Denkert C, von Minckwitz G, Darb-Esfahani S, Lederer B, Heppner BI, Weber KE, Budczies J, Huober J, Klauschen F, Furlanetto $\mathrm{J}$, et al. Tumour-infiltrating lymphocytes and prognosis in different subtypes of breast cancer: a pooled analysis of 3771 patients treated with neoadjuvant therapy. Lancet Oncol. 2018;19(1):40-50.

26. Meng XY, Shi MJ, Chen JF, Liao Y, Hu BW, Hireche A. Association between the TACC3 rs798766 Polymorphism and Risk of Urinary Bladder Cancer: A Synthesis Based on Current Evidence. Dis Markers. 2017;2017:7850708.

27. Santoiemma PP, Powell DJ Jr. Tumor infiltrating lymphocytes in ovarian cancer. Cancer Biol Ther. 2015;16(6):807-20.

28. Weiss SA, Han SW, Lui K, Tchack J, Shapiro R, Berman R, Zhong J, Krogsgaard M, Osman I, Darvishian F. Immunologic heterogeneity of tumor-infiltrating lymphocyte composition in primary melanoma. Hum Pathol. 2016;57:116-25.

29. Shi L, Zhang Y, Feng L, Wang L, Rong W, Wu F, Wu J, Zhang K, Cheng S. Multi-omics study revealing the complexity and spatial heterogeneity of tumor-infiltrating lymphocytes in primary liver carcinoma. Oncotarget. 2017;8(21):34844-57.

\section{Figures}

A

B
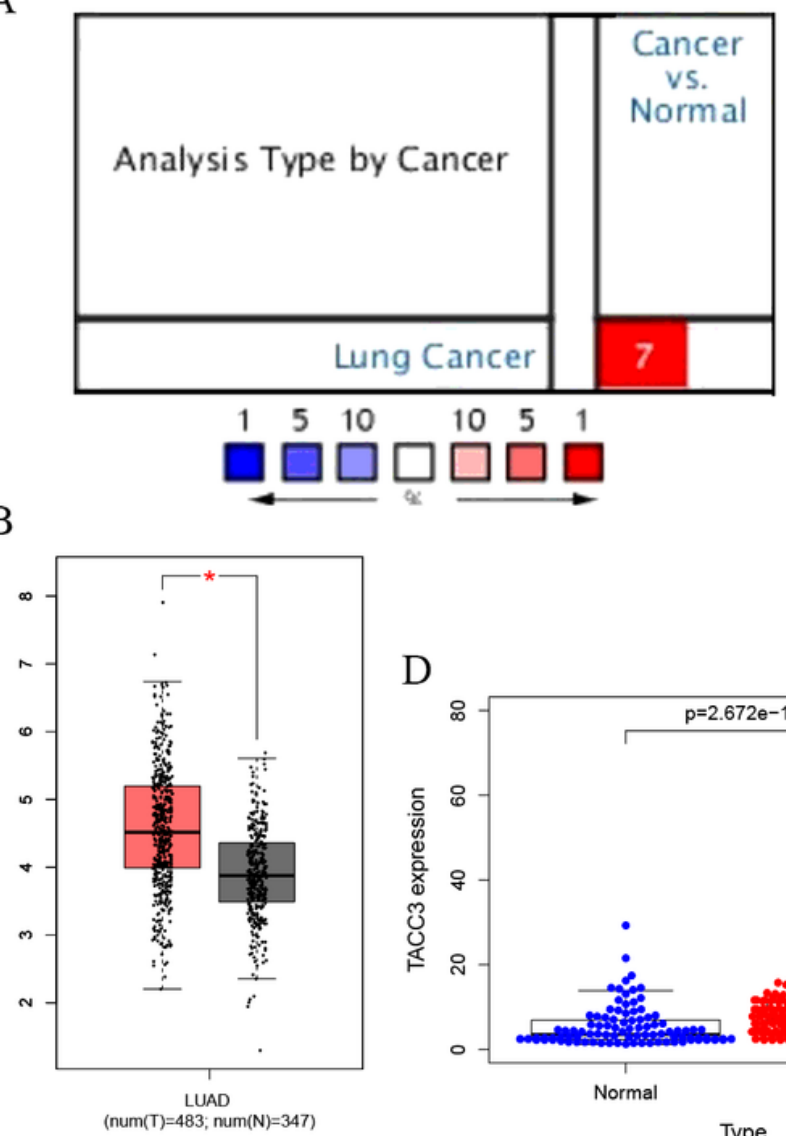

D

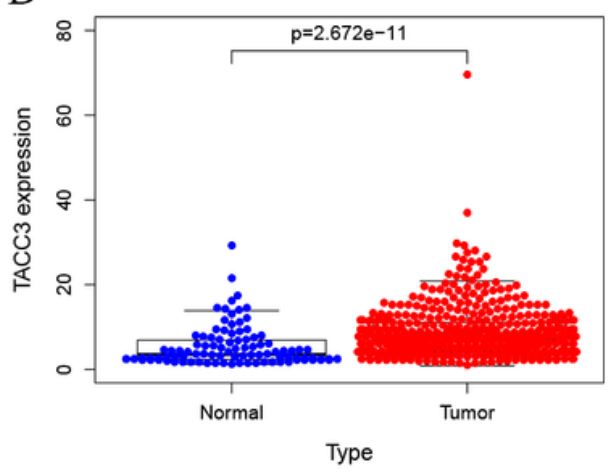

C

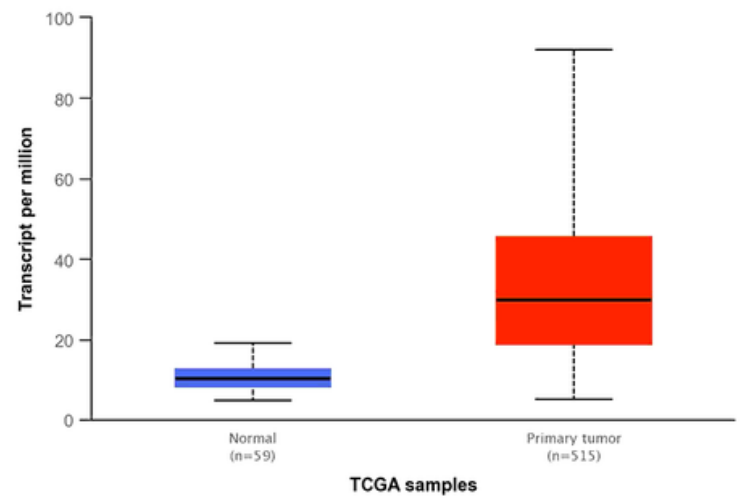

E

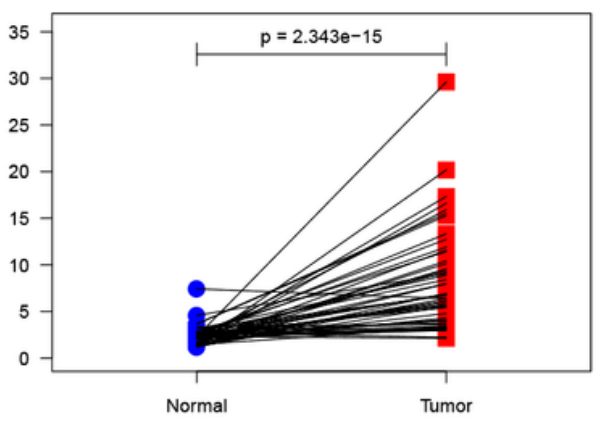

Figure 1 
TACC3 expression levels in LUAD cancer using 4 databases. (A) Oncomine database. Cell color is determined by the best gene rank percentile for the analyses within the cell. (B) GEPIA database. Significant differences cancer types were shown in red, $p<$ 0.05. (C) UALCAN database. normal vs tumor, $p=1.6235 \mathrm{e}-12$. (D) TCGA database analyzed by $R$ script. $p=2.672 \mathrm{e}-11$. (E) TACC3 expression in a paired comparison of LUAD and their adjacent normal tissues. Data were extracted from TCGA database, $p=$ 2.343e-15.
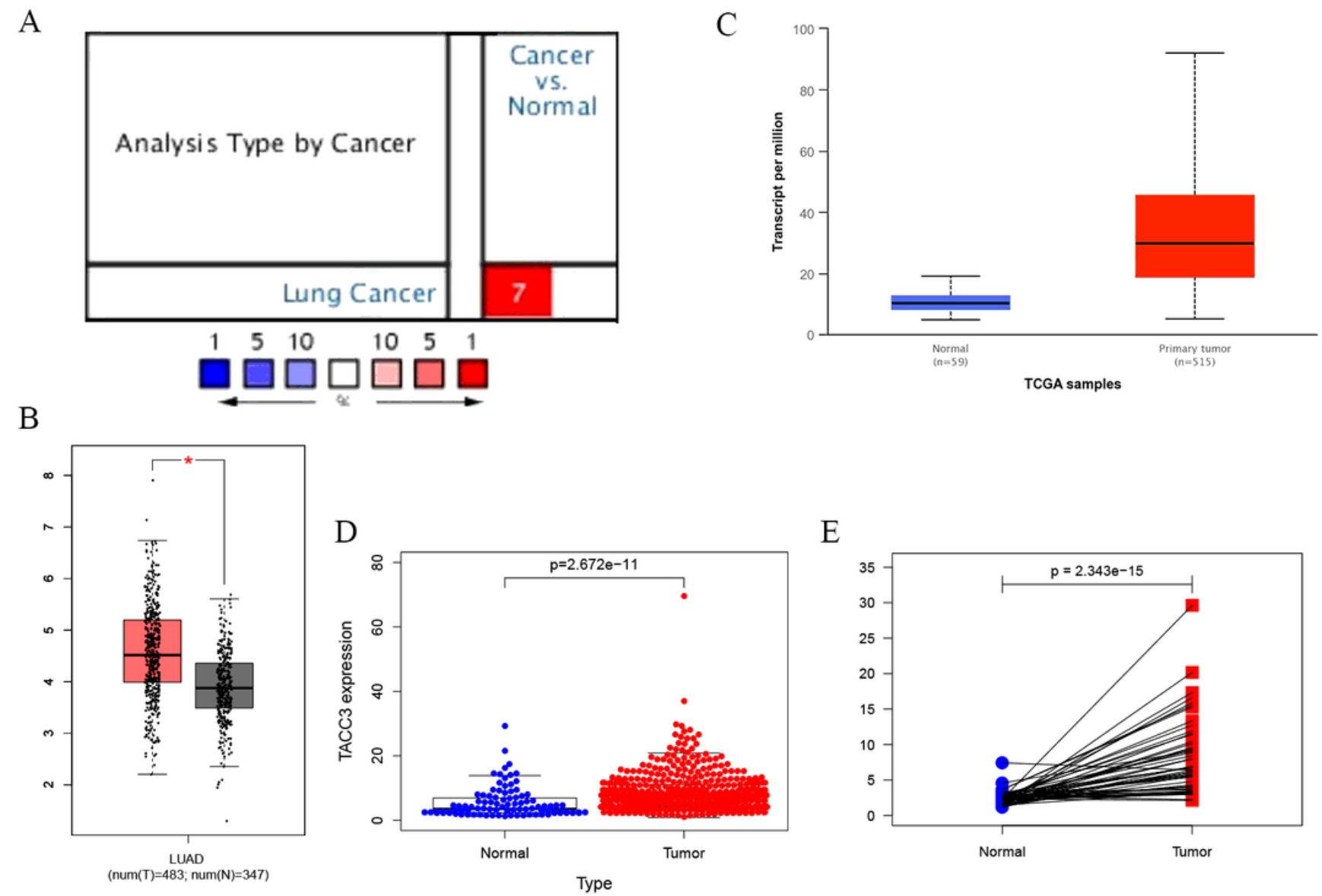

$\mathrm{E}$

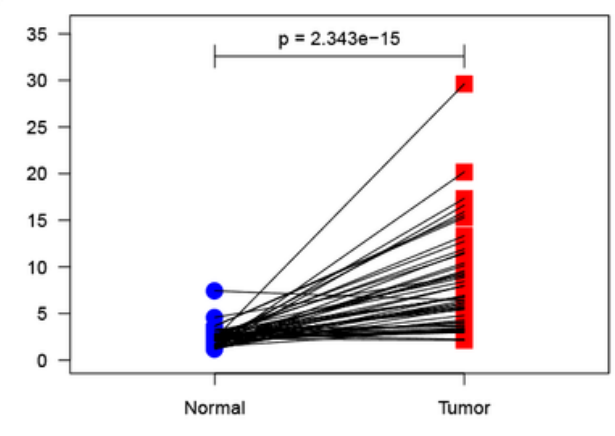

\section{Figure 1}

TACC3 expression levels in LUAD cancer using 4 databases. (A) Oncomine database. Cell color is determined by the best gene rank percentile for the analyses within the cell. (B) GEPIA database. Significant differences cancer types were shown in red, $p<$ 0.05. (C) UALCAN database. normal vs tumor, $p=1.6235 \mathrm{e}-12$. (D) TCGA database analyzed by $R$ script. $p=2.672 \mathrm{e}-11$. (E) TACC3 expression in a paired comparison of LUAD and their adjacent normal tissues. Data were extracted from TCGA database, $p=$ 2.343e-15. 

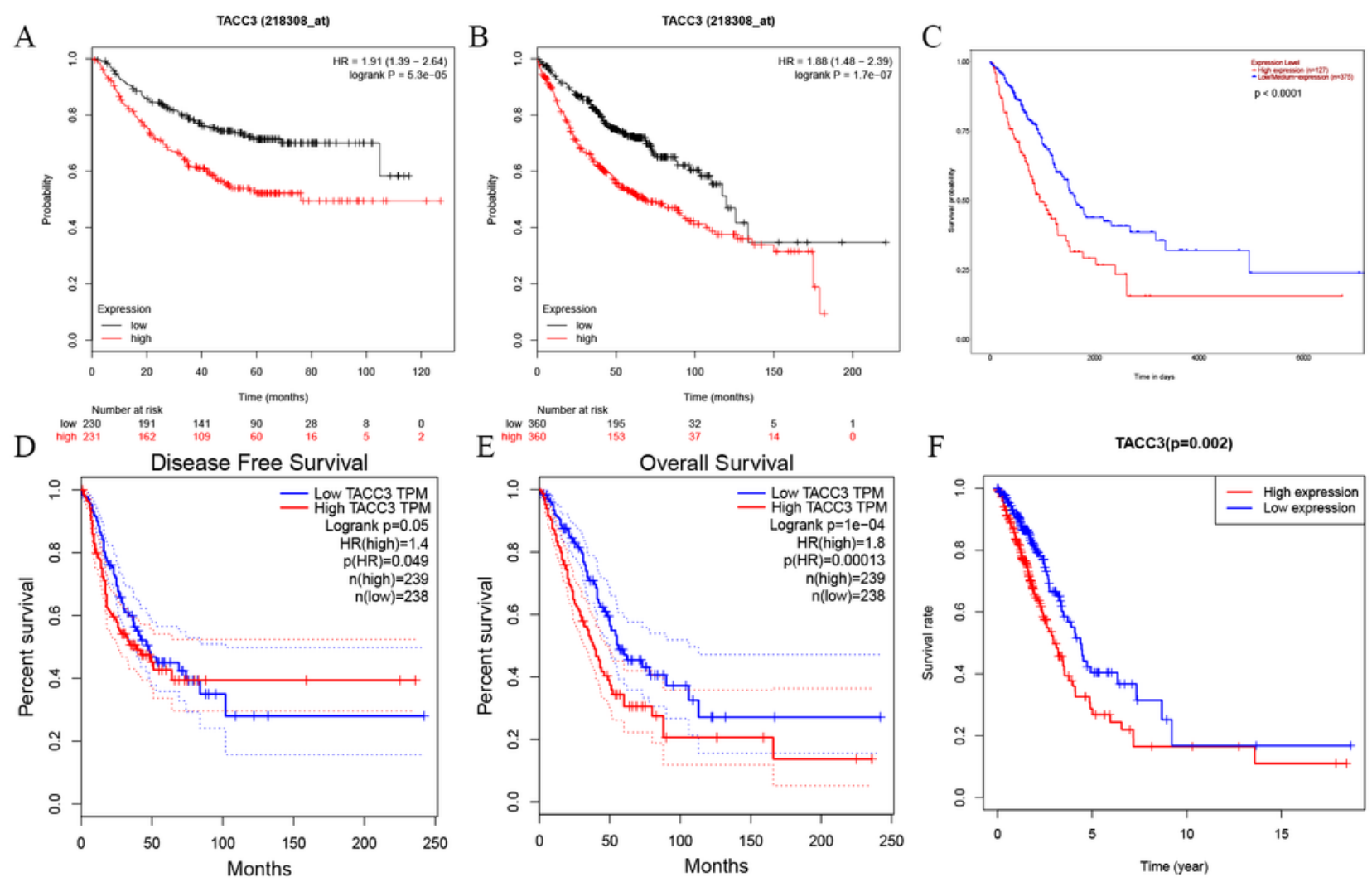

Figure 2

Kaplan-Meier survival curves of TACC3 expression levels determined using 4 databases. (A, B) OS and RFS in Kaplan-Meier Plotter database. (C, D) OS and DFS in GEPIA database. (E) OS in UALCAN database. (F) OS in TCGA database. OS: Overall Survival; RFS: Relapse-Free Survival; DFS: Disease Free Survival.
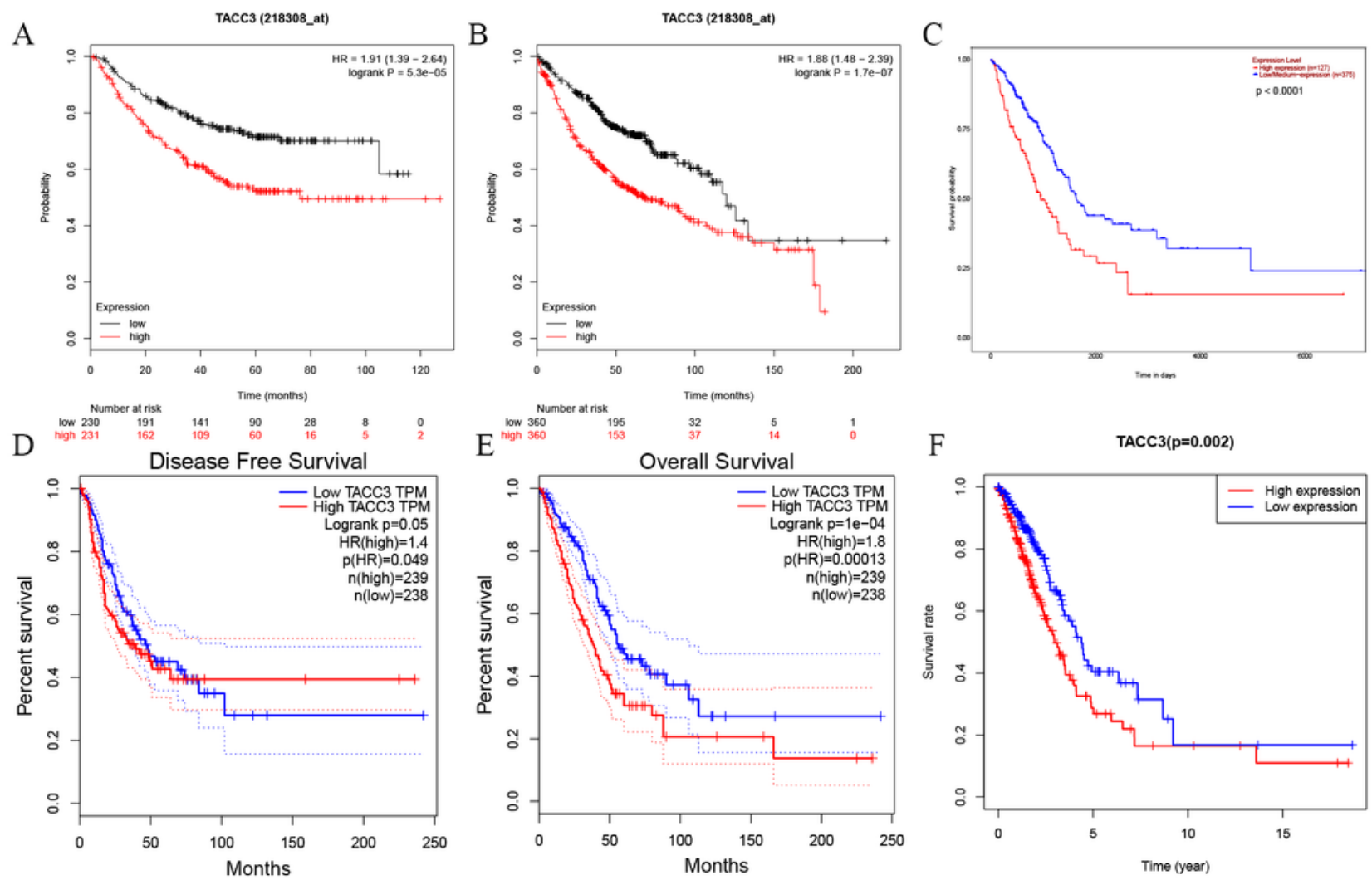
Figure 2

Kaplan-Meier survival curves of TACC3 expression levels determined using 4 databases. (A, B) OS and RFS in Kaplan-Meier Plotter database. (C, D) OS and DFS in GEPIA database. (E) OS in UALCAN database. (F) OS in TCGA database. OS: Overall Survival; RFS: Relapse-Free Survival; DFS: Disease Free Survival.

A

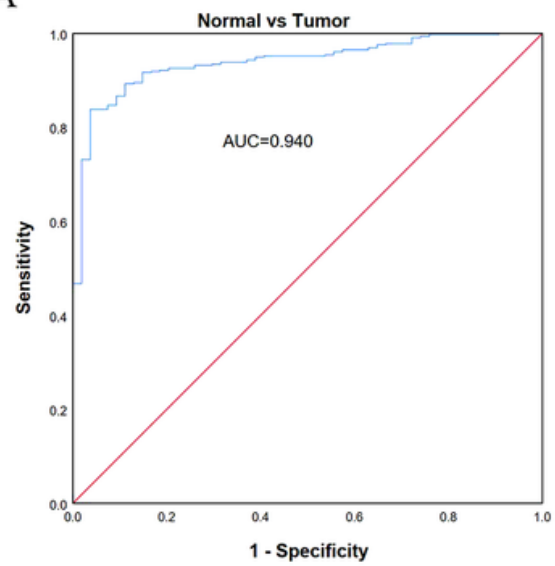

$\mathrm{D}$

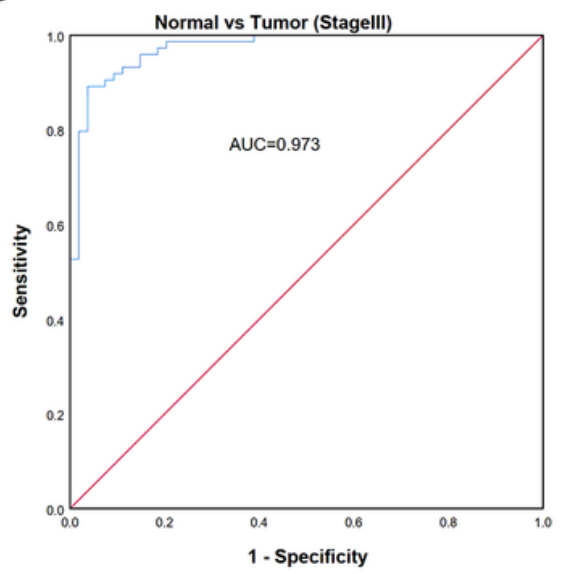

B

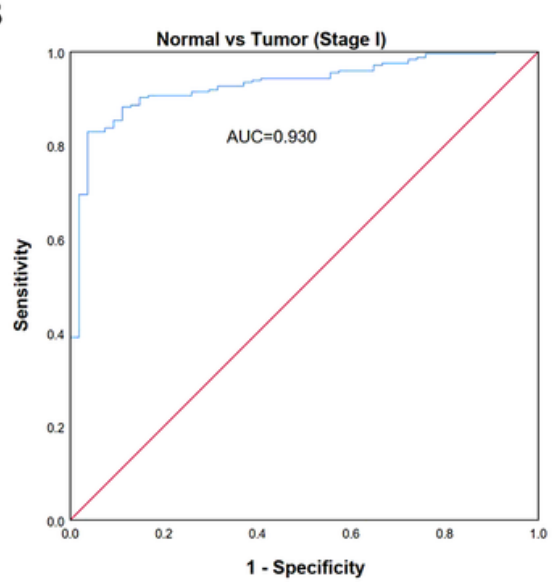

E

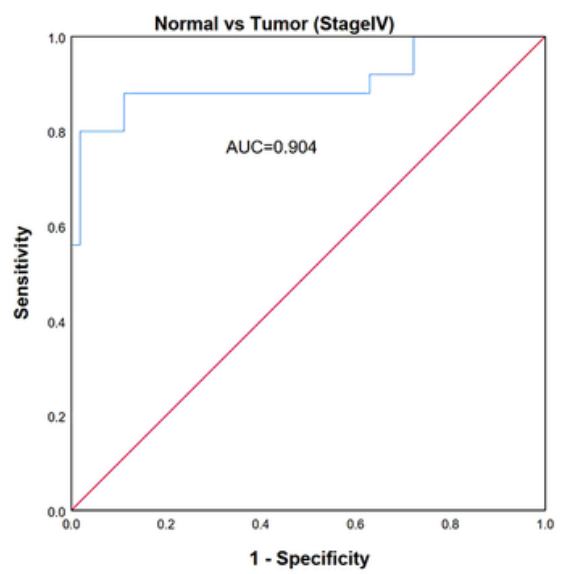

$\mathrm{C}$

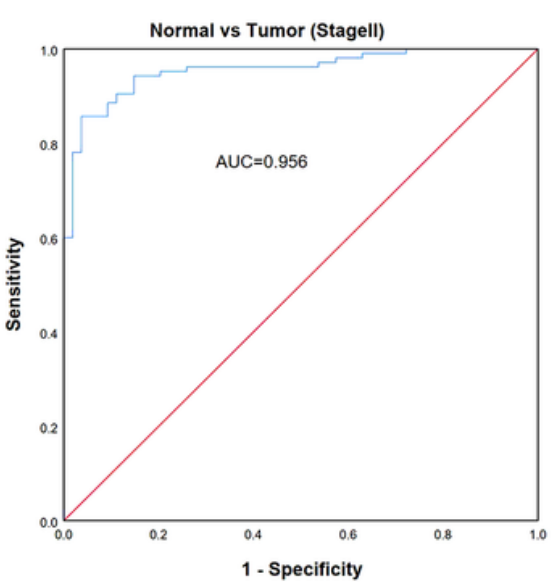

\section{Figure 3}

Diagnosis value of TACC3 expression in LUAD using ROC analysis. (A) ROC curve for TACC3 mRNA expression in normal and LUAD tissues. (B-E) ROC curves for TACC3 mRNA expression in different stages (I, II, III, IV) of LUAD. All AUCs were shown in each ROC curve. AUC: area under ROC curve. 
A

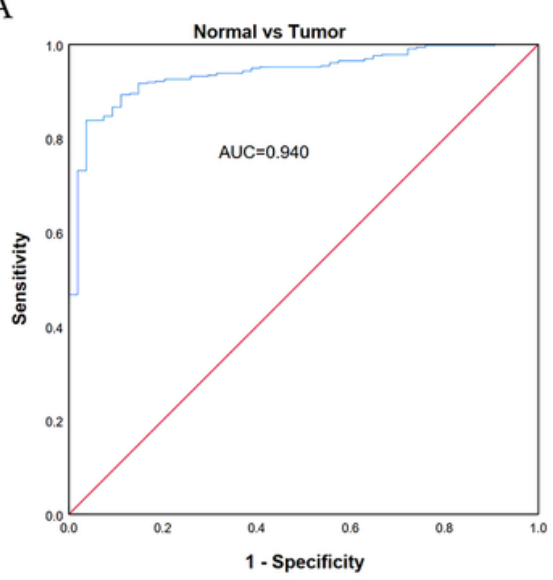

$\mathrm{D}$

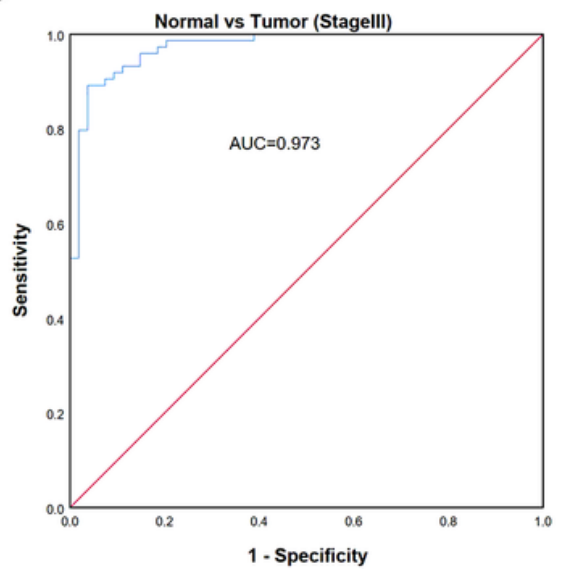

B

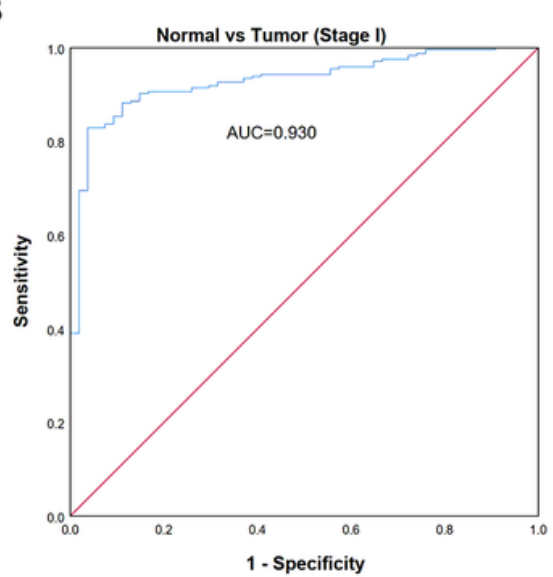

E

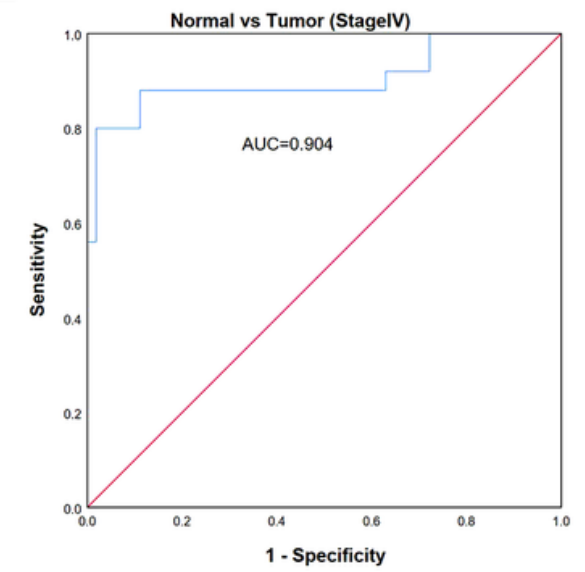

$\mathrm{C}$

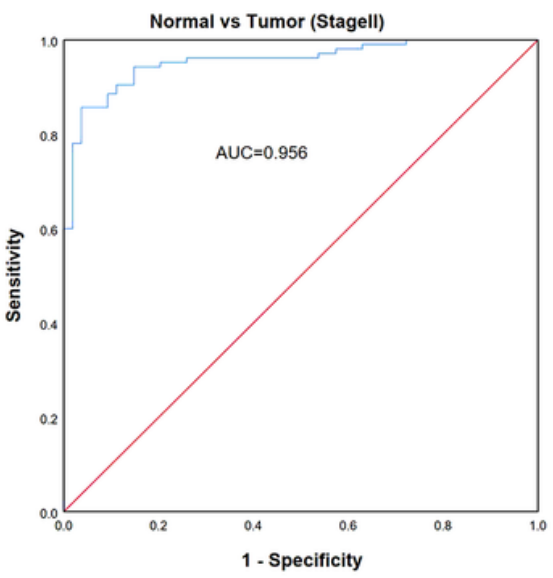

\section{Figure 3}

Diagnosis value of TACC3 expression in LUAD using ROC analysis. (A) ROC curve for TACC3 mRNA expression in normal and LUAD tissues. (B-E) ROC curves for TACC3 mRNA expression in different stages (I, II, III, IV) of LUAD. All AUCs were shown in each ROC curve. AUC: area under ROC curve. 


\section{Hazard ratio}

age

$(N=439) \quad(1.01-1.0)$

gender

$(N=439)$

0.97
$(0.70-1.3)$

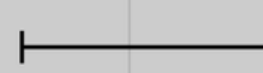

stage

$(N=439)$

$(1.21-1.91)$

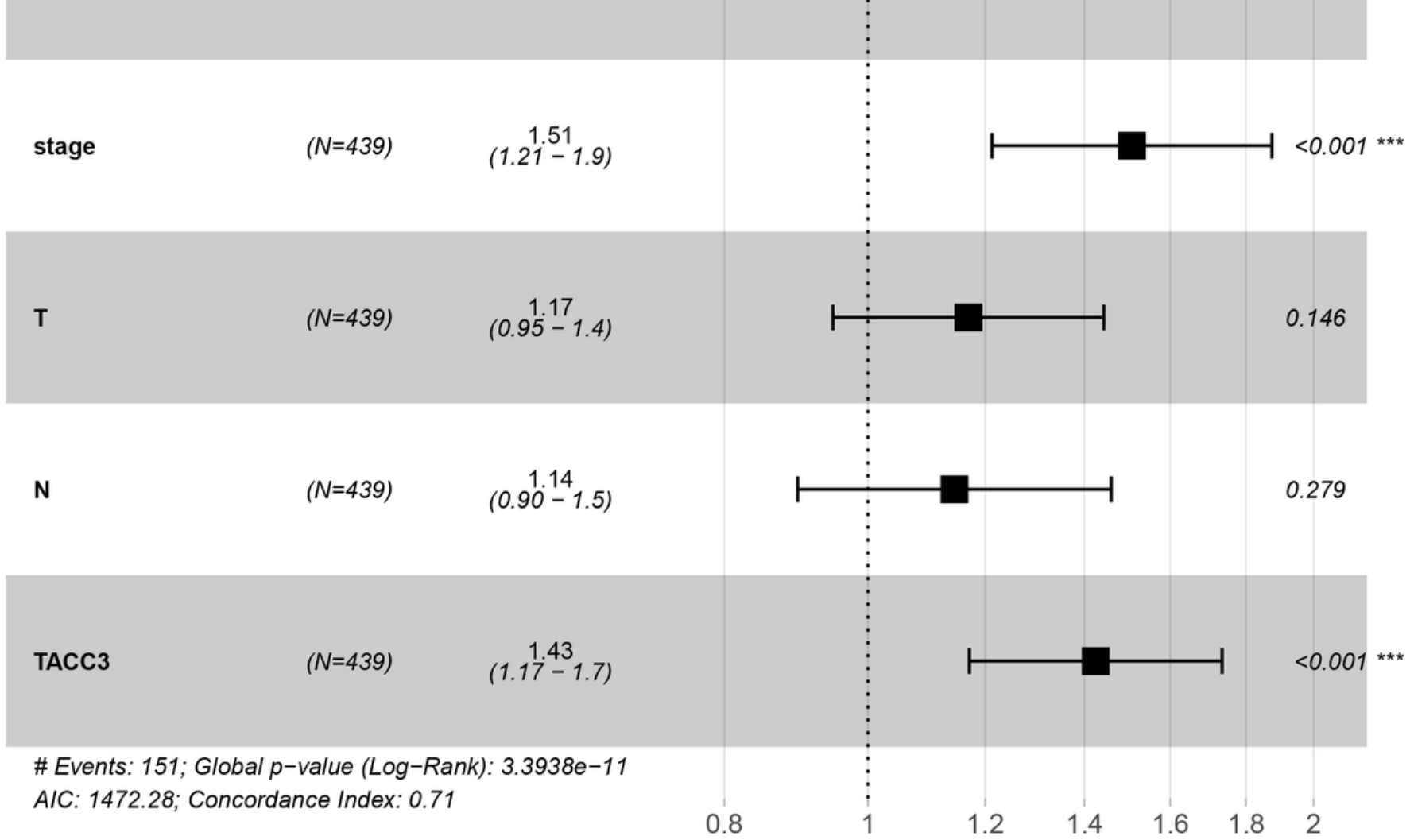

\section{Figure 4}

Multivariate Cox regression analysis shows that TACC3 is an independent risk factor for OS among LUAD patients. ${ }^{\star \star} \mathrm{p}<0.01$, ${ }^{\star \star \star} \mathrm{p}$ $<0.001$. 


\section{Hazard ratio}

age

$(N=439) \quad(1.01-1.0)$

gender

$(N=439)$

0.97
$(0.70-1.3)$

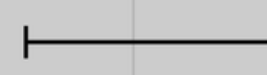

0.857

stage

$(N=439)$

$(1.21-1.91)$

$0.009^{* *}$

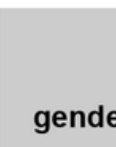

$$
(0.70-1.3)
$$
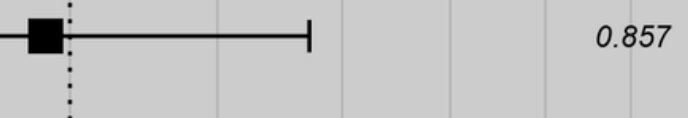

$\mathbf{T}$

$(N=439)$

$$
\begin{gathered}
1.17 \\
(0.95-1.4)
\end{gathered}
$$

0.146
N
$(N=439)$
$\left(\begin{array}{c}1.14 \\ \left(0.90^{-1}\right.\end{array}\right.$
$(0.90-1.5)$

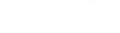

TACC3

$(N=439)$

$$
\begin{gathered}
1.43 \\
\left(1.17^{-1.7)}\right.
\end{gathered}
$$

\# Events: 151; Global p-value (Log-Rank): 3.3938e-11

AIC: 1472.28; Concordance Index: 0.71

\section{Figure 4}

Multivariate Cox regression analysis shows that TACC3 is an independent risk factor for OS among LUAD patients. ${ }^{\star \star} p<0.01$, ${ }^{\star \star \star} p$ $<0.001$. 
A

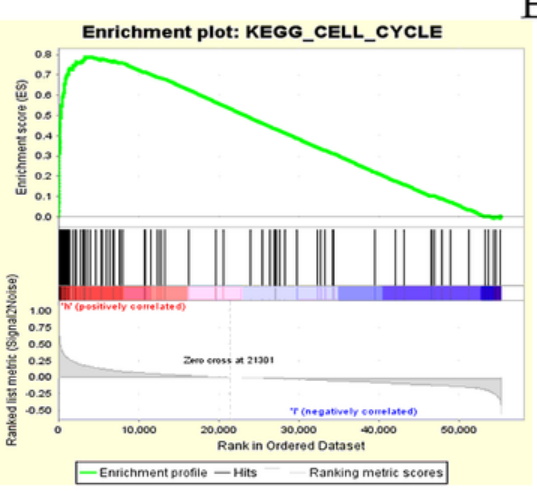

D

Enrichment plot:

KEGG_PROGESTERONE_MEDIATED_OOCYTE_MATURA
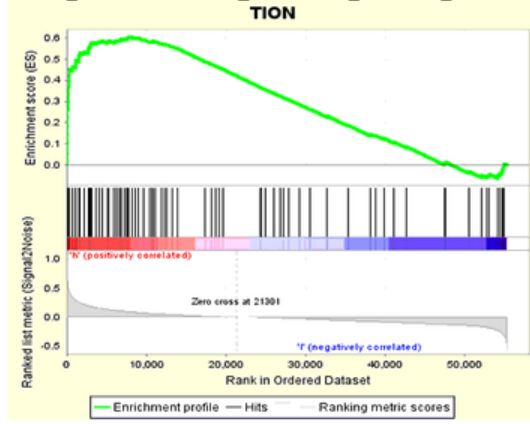

G

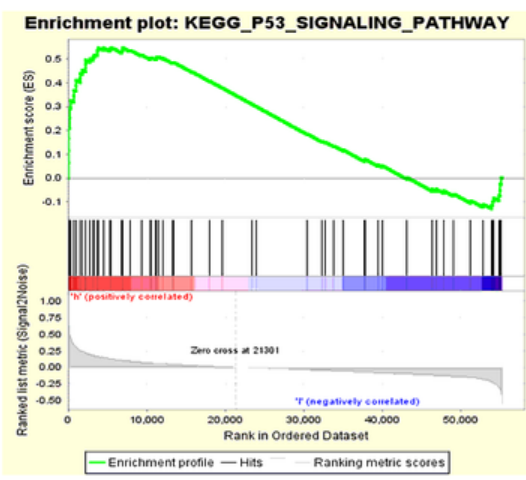

B

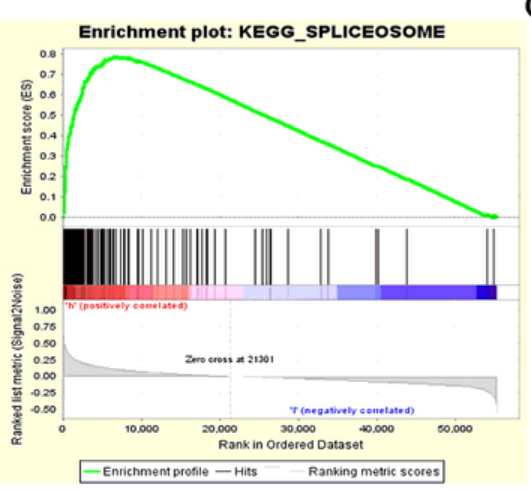

E

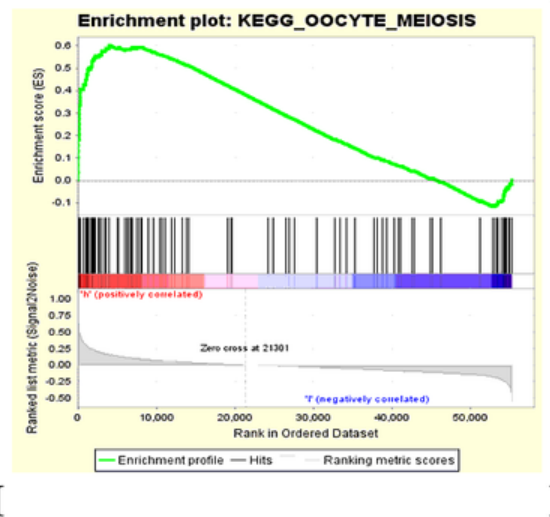

$\mathrm{H}$

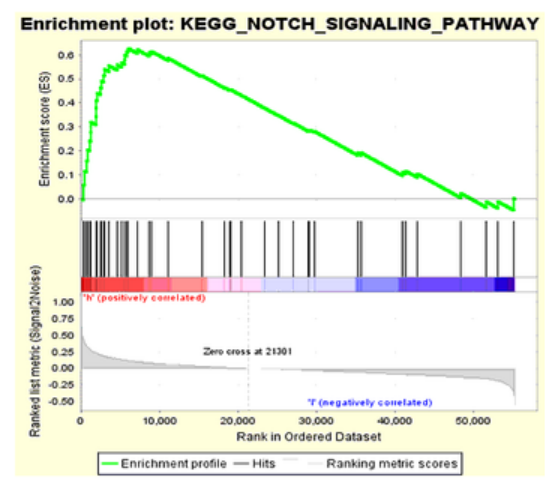

C

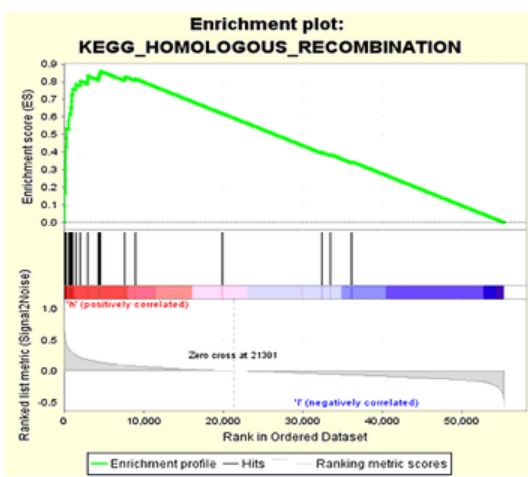

F

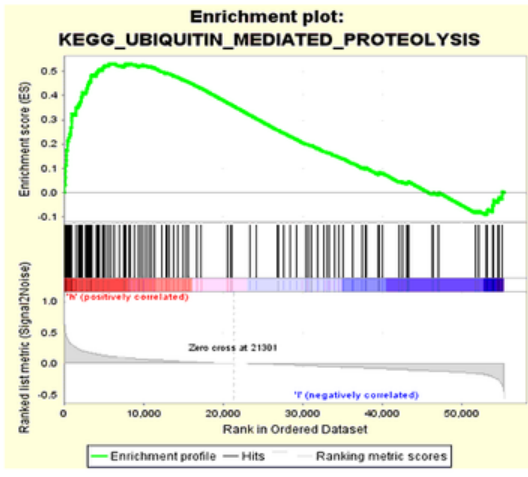

I

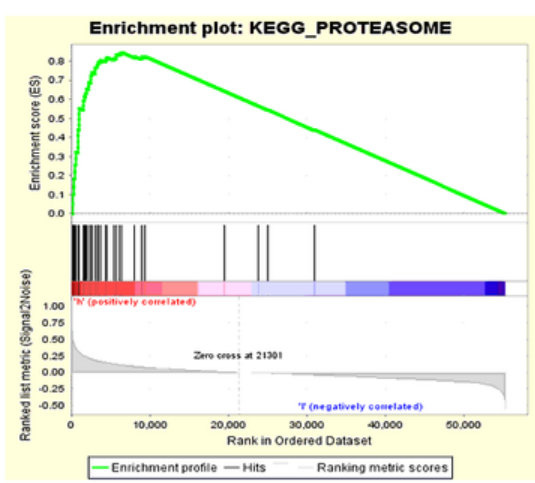

\section{Figure 5}

Enrichment plots in LUAD cases with high TACC3 expression using GSEA 3.0. GSEA results showing differential enrichment of genes related various types of pathways. (A) cell cycle, (B) spliceosome, (C)homologous recombination, (D) progesterone mediated oocyte maturation, (E) oocyte meiosis, (F) ubiquitin mediated proteolysis, (G) p53 signaling pathway, (H) Notch signaling pathway and (I) proteasome. 
A

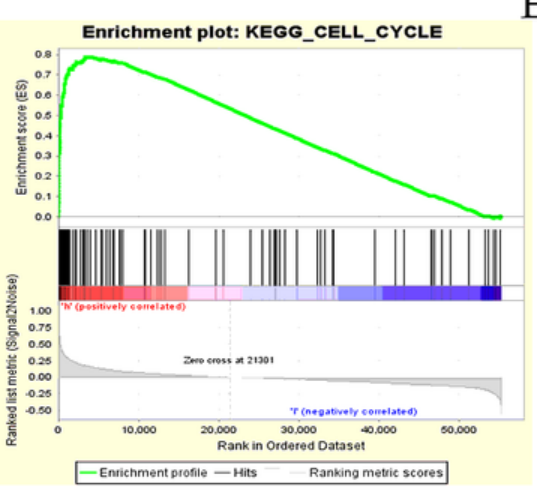

D

Enrichment plot:

KEGG_PROGESTERONE_MEDIATED_OOCYTE_MATURA
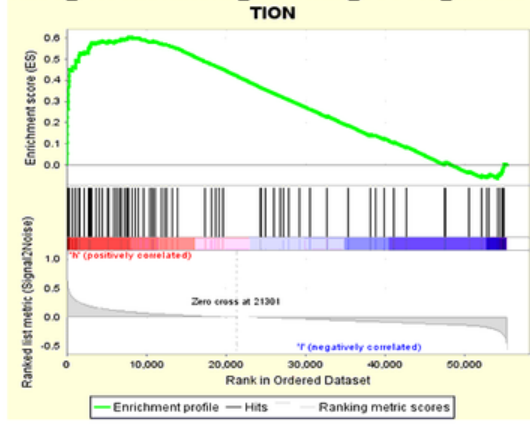

G

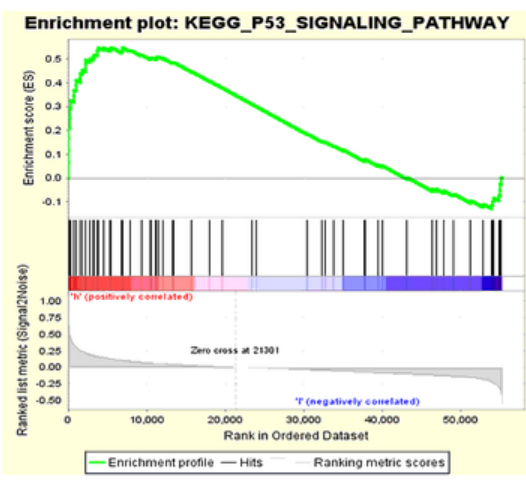

B

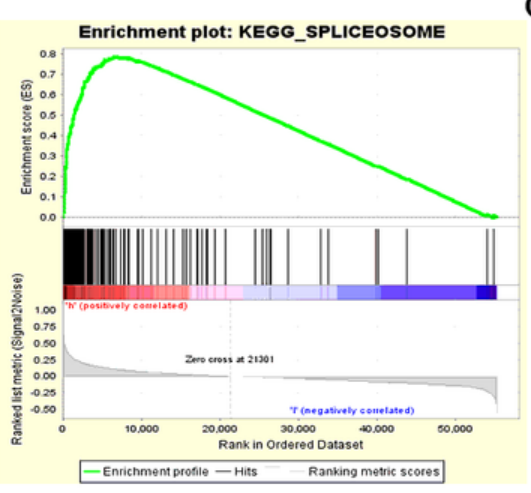

E

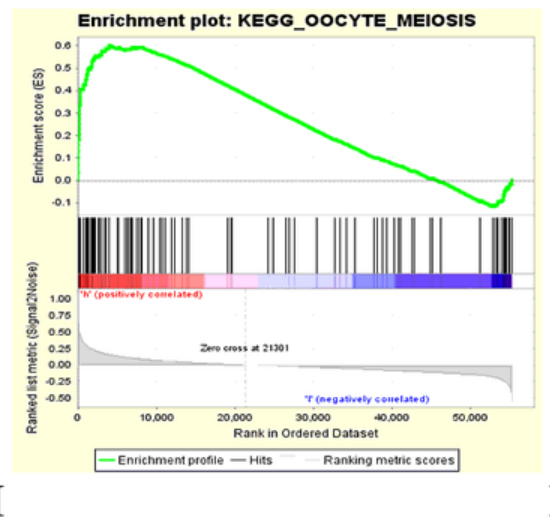

$\mathrm{H}$

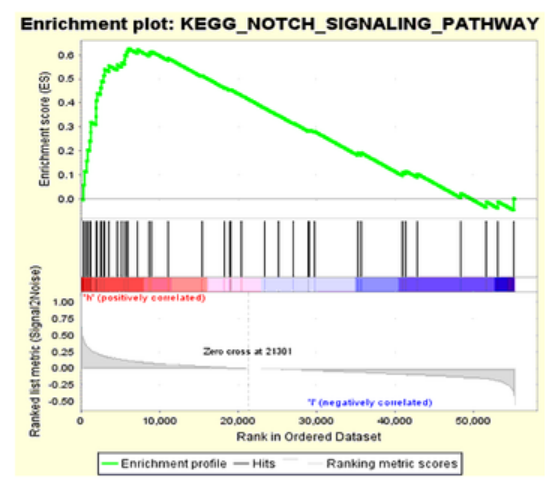

C

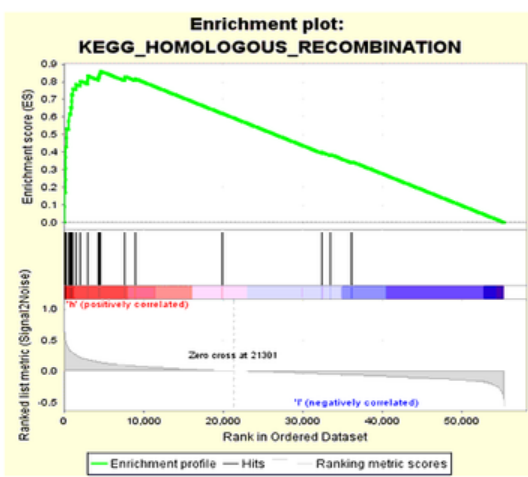

F

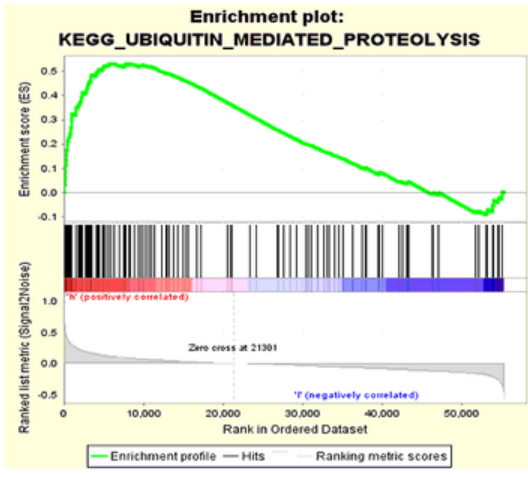

I

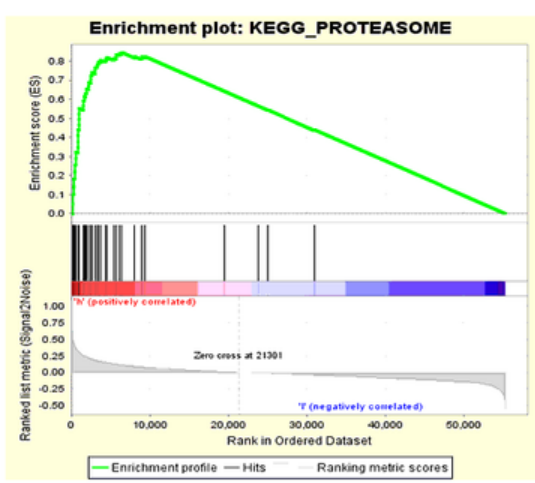

\section{Figure 5}

Enrichment plots in LUAD cases with high TACC3 expression using GSEA 3.0. GSEA results showing differential enrichment of genes related various types of pathways. (A) cell cycle, (B) spliceosome, (C)homologous recombination, (D) progesterone mediated oocyte maturation, (E) oocyte meiosis, (F) ubiquitin mediated proteolysis, (G) p53 signaling pathway, (H) Notch signaling pathway and (I) proteasome. 


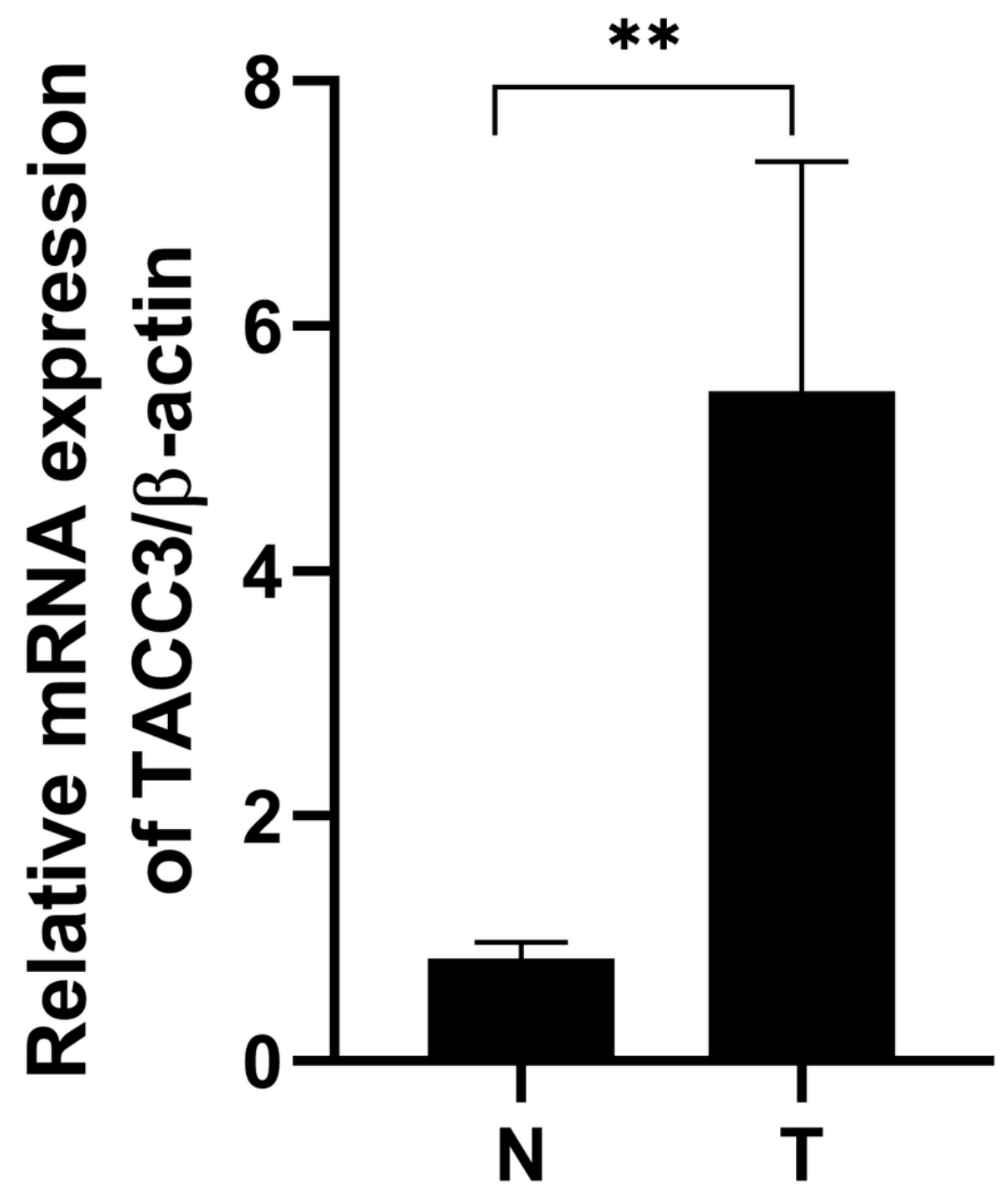

Figure 6

TACC3 mRNA expression is frequently upregulated in LUAD tissues. T: LUAD tissues; $\mathrm{N}$ : noncancerous tissues. The results were shown with Mean \pm SD. ${ }^{*} \mathrm{p}<0.01$. 


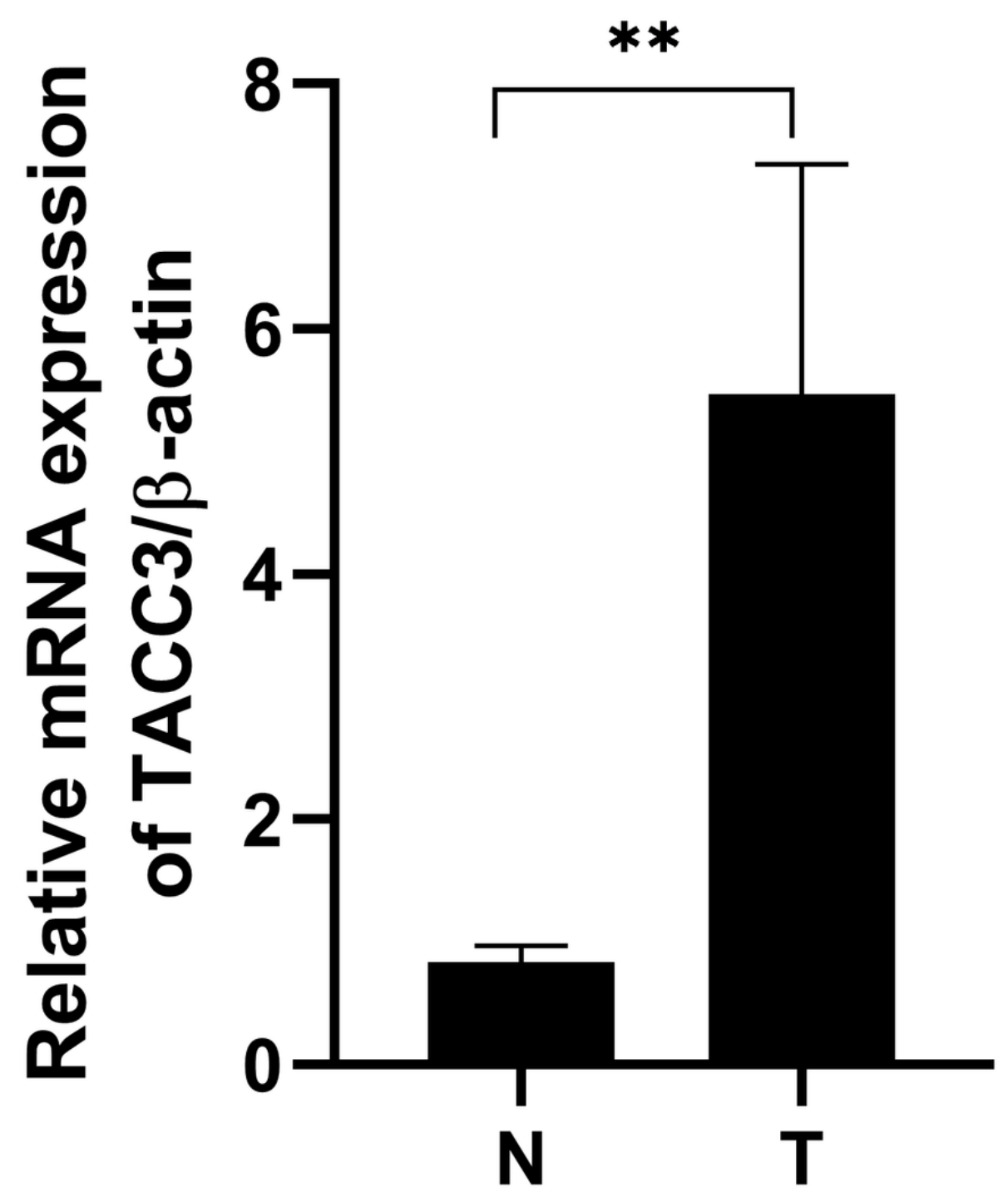

Figure 6

TACC3 mRNA expression is frequently upregulated in LUAD tissues. T: LUAD tissues; $\mathrm{N}$ : noncancerous tissues. The results were shown with Mean \pm SD. ${ }^{*} \mathrm{p}<0.01$. 